\title{
Tracking Police Responses to "Hot" Vehicle Alerts: Automatic Number Plate Recognition and the Cambridge Crime Harm Index
}

\author{
Baljeet Sidhu $^{1}$ - Geoffrey C. Barnes ${ }^{2,3}$. \\ Lawrence W. Sherman ${ }^{3,4}$
}

Published online: 30 October 2017

C The Author(s) 2017. This article is an open access publication

\begin{abstract}
Research Question Are selective decisions to dispatch police cars for interception of vehicles identified by 'live alerts' from fixed cameras using an Automatic Number Plate Recognition (ANPR) database associated with the highest levels of harm across all live alerts?

Data This study examined 70.3 million vehicle registration marks read by Fixed ANPR cameras in the West Midlands Police area in April 2015, from which 12,581 live alerts were generated with many repeats, for 1488 unique vehicles identified. A random sample of 210 of these unique alerts was drawn for detailed analysis.

Methods Cambridge Crime Harm Index values were applied to each of the 210 cases in the sample, with mean values computed and contrasted for alerts generating dispatched responses vs. no dispatch, interceptions vs. no interceptions and consequences imposed on drivers vs. no consequences.

Findings The mean Cambridge Crime Harm Index (CCHI) value of the alerts leading to a dispatched response was $58 \%$ lower (59 CCHI days vs. 141) than the value of alerts not leading to a dispatch. The harm level of alert dispatches leading to interception was $57 \%$ lower (67 vs. $107 \mathrm{CCHI}$ days) than those not intercepted. The harm level of interceptions leading to consequences was $57 \%$ lower (46 vs. $106 \mathrm{CCHI}$ days).

Conclusions While resource limitations may affect these outcomes, there is great potential value in creating an automated CCHI calculator to inform the professional
\end{abstract}

Lawrence W. Sherman

1s434@cam.ac.uk

1 West Midlands Police, Birmingham, UK

2 Western Australia Police, Perth, Australia

3 University of Cambridge, Cambridge, UK

4 University of Maryland, College Park, USA 
judgment of all police professionals involved in screening and responding to live alerts from ANPR.

Keywords ANPR · Policing · Crime Harm Index · Police responses (automatic number plate recognition) resource allocation $\cdot$ Discretion

\section{Introduction}

This study examines the allocation of scarce police response resources to "live time" Automatic Number Plate Recognition (ANPR) alerts of vehicles that are sought by police in connection with an offence. ANPR technology has been in growing use since 1976 (Gaikwad and Barole 2014), yet no research published to date has tracked police discretion in immediate responses to live time alerts. This study examines those responses in a large urban area with over 4000 "hits" generating some 50 unique vehicle alerts per day.

Live time ANPR alerts are notifications of vehicles' locations in real time (through ANPR technology and cameras) to police control rooms, where decisions are made about assigning a response. Police cars may not always be available, within a narrow window of time, to respond immediately to vehicles on freeways travelling 70 miles per hour. The tracking question for the study is whether the live alerts that do receive responses are intercepting those vehicles associated with the highest levels of harm from crime. The answer is no: they are not.

This study describes the current practice and policy of targeting live time alerts. It further explores the total severity of crime that is identified by ANPR alerts as measured by the Cambridge Crime Harm Index, or CCHI (Sherman et al. 2016), and how the CCHI can be used to assist in decision making for future targeting of live time responses. The analysis in this study shows that in one month in 2015, only $23 \%$ of the total alerts were assigned to rapid response by police patrol cars in order to stop the wanted vehicles. These responses related to only $11 \%$ of the total CCHI harm associated with all alerts combined. The article describes how targeting based on CCHI values could be coupled with the police control room operators' professional judgement to target over $90 \%$ of harm with immediate responses.

\section{Context}

A key challenge facing police world-wide is to make better police resource deployment choices with finite numbers of staff, and (in some but not all countries) tighter police budgets. As in many kinds of demand for police services, the volume of ANPR alerts is so large that the police almost invariably have a far higher number of alerts than they can respond to. Given the rapid growth of ANPR surveillance in the UK, the USA (where it is known as Licence Plate Recognition or LPR) and other countries, the question of targeting responses will only become more pressing over time.

One tool for targeting police resources more selectively is the Cambridge Crime Harm Index (Sherman et al. 2016), a crime harm measurement system that captures the level of harm associated with a criminal offence by placing a certain weight in numerical value for the harm caused by the offence. Using the $\mathrm{CCHI}$, the harm 
associated with a crime is measured by the number of days prison sentence the offence attracts as the "starting point" for judicial sentencing guidelines for a first time offender for the particular crime (see Cambridge CCHI for the exact number of days imprisonment recommended for over 800 offence categories).

This is the first study of its kind that has examined prioritisation of ANPR alerts. Whilst forces have clearly adopted prioritisation schemes, none of them have been examined using any measure of crime severity. This study provides what may be the first empirical evidence tracking the targeting (Sherman 2013) of live time ANPR alerts based on a crime severity measure.

\section{Growth of ANPR Systems}

Many police forces across the UK, including West Midlands Police, have invested substantially in ANPR technology to help achieve crime reduction, detection and public safety objectives. The UK has a sophisticated and comprehensive network of ANPR cameras across the length of the country, providing opportunities to systematically target criminals (National ANPR Conference 2014; Home Office 2013). The National ANPR Data Centre (NADC) recently held in excess of 17 billion records in its archives (National ANPR Data Centre 2014).

ANPR is used by police in two different ways to tackle crime. The first is through back tracking and searching the ANPR database for vehicles associated with crime as a reactive investigation. The second way is through live time targeting of criminally associated vehicles by police, as a proactive investigation. This is done in real time by way of police patrols responding to the alerts generated in the control room from ANPR cameras.

The high number of live time alerts that are generated by the ANPR system presents daily challenges to police discretion. In the West Midlands there are, on average, 70.3 million readings of wanted vehicle licence plates per month. This does not mean that there are 70.3 million alerts; it is the number of licence plates read and stored in the ANPR database per month. Out of these, on average, approximately 12,580 result in an alert that requires a response by police control room staff. Most of these 12,580 readings of licence plates (called vehicle registration marks or "VRMs") are of the same vehicles that are generating repeat alerts as they pass successive cameras. By analysing all the VRMs in the West Midlands police area to remove the repeat notices, the number of unique vehicles subject to alerts is between 1400 and 1500 per month, or about 50 per day.

The ANPR technology has improved considerably over the years with vast advances in accuracy, supported by the research done in the UK by Ramalingam et al. (2014) and with the research conducted by Gaikwad and Barole (2014). Both these studies show a very high accuracy rate in reading licence plates correctly. In conducting the research for this study, the first author found that over $98 \%$ of VRMs were accurate in identifying the vehicle registration number.

The growth and accuracy of this technology is far ahead of any evidence of its benefits. Only two rigorous tests of the outcomes of its use in live time have been published as of 2016, both of which were with mobile (in-car) rather than fixed location readers (Taylor et al. 2011; Lum et al. 2011). Neither of them found any crime reduction benefit associated with the plate-reading technology. 


\section{Setting Priorities for Live Time Monitoring}

Current policies for targeting responses to live alerts, in principle, give priority to serious offences over the lower level ones. In the West Midlands, the live time alerts are prioritised for resourcing using a pyramid-shaped tiered approach. The approach consists of prioritising vehicles recorded on three main systems-(1) The Police National Computer (PNC), (2) local and regional intelligence systems and (3) external systems such as the national vehicle licensing and insurance databases. PNC Alerts carry their own priority designations of high, medium and low. Intelligence alerts use a similar ordinal scale, which structures their allocation below PNC Alerts. At the bottom end of the pyramid, with the lowest priority and highest volume, are hits with licence numbers identified from external agency databases. Neither this, nor any other, system of priorities has been compared to standardized measure of seriousness, such as the Cambridge CHI.

\section{Research Question}

The general research question for this study is whether the responses to live alerts intercept those vehicles associated with the highest levels of harm from crime. This question requires us to answer four subordinate questions:

1. How are live time Automatic Number Plate Recognition (ANPR) System alerts currently assigned by West Midlands Police?

2. What is the distribution of crime harm across alerts and responses?

3. How can the Crime Harm Index be applied to prioritise resource

allocation across live time alerts?

4. Are higher harm alerts (hits) more likely to result in intercepts?

Answering these questions requires clarity in the terminology for using ANPR.

\section{Defining Key Terms}

Automatic Number Plate Recognition (ANPR) ANPR is a camera technology which automatically reads the VRMs of passing vehicles and matches them with other databases to establish if the vehicle passing has a warning marker on any of the databases. If it has, then the ANPR system generates an alert to the police control room staff. Otherwise the VRM (for every vehicle passing by) is simply recorded on the ANPR system for later analysis, if required. ANPR assets or cameras can be placed either on fixed locations, such as motorways and arterial routes, or in police patrol vehicles. All the ANPR assets used for this study are fixed.

Live Time ANPR Alerts A 'live time ANPR alert' is the term used to define the notification of a vehicle with a police interest marker to the police control room in live time as the VRM is read are captured by ANPR cameras. The police control room staff, 
who monitor the live time alerts, then decide whether an alert requires a response of deploying police officers to stop the vehicle.

ANPR Hotlists These are ANPR databases held by police forces locally and nationally. Vehicles of interest to the police are uploaded onto these databases (hotlists) for matching with live time alerts.

PNC Hotlist This is a national police database that includes entries of crimes where wanted persons are linked to a motor vehicle. The system, which received top priority in West Midlands at the time of the study, has an ANPR hotlist with details of vehicle registration plates linked with offences or other police matters such as vulnerable missing persons.

Central Motorway Police Group (CMPG) Hotlist The CMPG ANPR data hotlist is maintained by the Central Motorway Police Group ANPR intelligence manager. The list or dataset contains the details and VRMs of all the vehicles that are sought by the West Midlands region's motorway police department for offences sought by their officers. This hotlist is also monitored regularly and updated by CMPG's control room staff. Vehicles which are of interest locally to CMPG officers (for intelligence gathering or part of local police operations) are mainly placed on this hotlist. They may not be of national interest, and therefore, are not placed on the PNC hotlist. Some vehicles, due to the severity of the offence, have entries on both hotlists.

West Midlands Police (WMP) Hotlist West Midlands police have their own ANPR hotlist for vehicles that are of policing interest to the local force. This maybe for either a criminal offence or because of the driver's or occupant's vulnerability. This hotlist is maintained by the West Midlands Intelligence unit in consultation with CMPG's intelligence unit. This hotlist is monitored regularly by the control centre staff for live time alerts. The staff then decide whether to send a police patrol to intercept the vehicle.

External Agency Hotlists A variety of external hotlists are used to generate live time alerts. These include the "no-insurance database" hotlist, the UK Driver and Vehicle Licencing Agency (DVLA) hotlist, Her Majesty's Revenue and Customs (HMRC) hotlist (in relation to tax matters) and numerous other hotlists from other forces and agencies. Due to the high volume of alerts that are generated, the West Midlands Police does not monitor the external agency hotlists as a matter of routine, so these lists are generally not part of the alerts included in this study. The external lists are switched on if there is a planned operation or intelligence deems it is operationally suitable to do so.

Force 'Intelligence' and 'Command and Control' Systems All vehicles with local police interest markers and the vehicles that are stopped in the force area are recorded on the force intelligence system. The record includes the reason for the stop, and any subsequent action taken. The force 'command and control' system captures information in relation to every single police incident in the force area, including any response to an ANPR alert. The records include the response and action taken in relation to the incidents and details of deployments and resourcing decisions and considerations. 
Cambridge Crime Harm Index Values The Cambridge Crime Harm Index (CCHI) as developed by Sherman et al. (2016), with further supportive work by Weinborn et al. (2015) and Bland (2014), assigns crime harm values to all criminal offences. The crime harm value here is calculated using the recommended (not actual) starting point for a sentence in days of imprisonment that the particular crime attracts for a first time offence, according to judicial sentencing guidelines.

In this research, crime harm is assigned to the vehicle which is linked to the offence, with the harm value relevant to the offence for which the occupant of the vehicle is sought. For example, if the occupant of the vehicle is wanted in connection with a 'theft of a motor vehicle,' then the value assigned is 15 , and if it is for 'making off without payment' (bilking) then it is 3 . The value is much higher for higher harm offences such as wounding, rape and manslaughter. The CCHI values used in this study are based on Bland and Ariel (2015). Table 1 includes examples of some high and low CCHI value alerts found in the study's sample of ANPR alerts.

\section{Data}

For the purpose of this research, data from the month of April 2015 had been collated from all fixed ANPR assets within the West Midlands Police (WMP) and Central Motorway Police Group (CMPG) areas. The month of April 2015 has been selected as it is fairly typical of most months of the year in terms of volume and nature of the ANPR alerts. This has been established through force ANPR analysis regarding seasonality and temporal work conducted regularly within the force. Furthermore, due to large volumes of data that ANPR collates and reads, one month's data was the maximum that available research resources could subject to manual checking across the many computer systems.

The complete data set for April 2015 included all ANPR read counts and alerts in WMP (70.3 million VRM Reads) recorded by ANPR during the month. Out of 70.3

Table 1 Example of high and low Crime Harm Index values

High and low crime harm offences and CHI Values

$\begin{array}{ll}\text { High crime harm offences/alerts } & 548 \\ \text { Registered sex offender/SOPO conditions } & 548 \\ \text { Drugs dealing_ class A } & 731 \\ \text { Firearms possession/drugs dealing class A } & 26.5 \\ \text { Distraction burglary/theft/handling } & 182 \\ \text { Child sexual exploitation/medium risk missing person } & 0 \\ \text { Low crime harm offences/alerts } & 5 \\ \text { Missing person enquiry } & 3 \\ \text { Disqualified driver } & 1.5 \\ \text { Making off without payment } & 0.96 \\ \text { Theft-shoplifting } & 5 \\ \text { Drink drive } & \end{array}$


million reads, there were 12,581 live-time alerts. Of these 12,581 alerts, 7253 were from the PNC Hotlist, 3840 from the CMPG and 1488 from the WMP Hotlist. As some vehicles generated multiple alerts during the whole month, further calculations established that after removing the repeat VRM alerts, there were a total of 1488 unique VRM alerts in the month.

The data for the above 1488 ANPR alerts was derived from a multiple of data sources. The "Back office function" (BOF) data base, where all ANPR records are stored, is the main source of all ANPR data. BOF contains data reads from over 70 million VRM reads per month in the West Midlands. This equates to over 2 million VRM reads per day. All the reads and those that resulted in alerts due to the vehicle being linked to an offence were taken from this data system. Live time entries are monitored by the Central Motorway Police Group's Regional Control Centre (RCC) in the West Midlands. The VRM alerts used in this research are from the three main ANPR hotlists described earlier (PNC, West Midlands Police, CMPG).

\section{Methods}

The Cambridge Crime Harm Index has been used to map the crime harm across the identified sample data for this research. The month of April 2015 produced a total of 1488 unique VRMs that were linked to alerts. This was further refined into 1401 alerts, as some of these VRMs were on all three hotlists (PNC, WMP and CMPG hotlists). After removing the duplicate alerts for the same vehicle at the same time from the other hotlists, the number of 1401 VRM alerts was established.

Due to the large number of manual checks required to answer the questions posed by this study, all the 1401 hits were put in a randomised order using an online randomiser. From the randomly sorted list of VRM alerts, the author fully researched and analysed the first 210 randomly sorted alerts, the maximum number of VRM alerts that were analysed in the time available.

Each of the 210 alerts was subject to a number of checks on police systems to identify the cause of the alert, the deployment decision taken, whether the vehicle had been stopped, the end result. Firstly, each VRM was checked on BOF to confirm its accuracy. BOF was further searched to identify the cause of the alert. This required manual searching of reports on BOF to establish the accurate reason. The alert was then subjected to another manual check on the force 'linked-intelligence' system which incorporates both the force command and control and intelligence systems. This check was necessary and the only way to find out if (1) an alert was responded to by the police control room staff though allocation of resources, (2) the vehicle was indeed intercepted and (3) there was a positive action taken against the occupants of the vehicle. This positive action is called a 'consequence' for the suspect throughout this study. Examples of a 'consequence' would be arrests made of suspects, suspects reported for summons, a suspect been cautioned or the vehicle been seized by the police. From the detailed examination of the sample data, it became evident that the 210 alerts represented many different offences and crimes. The first author grouped these crimes into 34 categories and then into ' 16 key' categories as per Table 2 to simplify analysis and the explanation thereafter for the reader: 
Table 2 Sixteen key offence categories

\begin{tabular}{ll}
\hline Key offence categories & Total \\
\hline Crime - General & 9 \\
Drink drive offences & 17 \\
Drugs offences & 23 \\
Firearms offences & 3 \\
Human exploitation & 3 \\
Illegal employment & 1 \\
Intelligence & 1 \\
Missing person & 6 \\
No hits & 4 \\
Obstructing justice & 6 \\
Prisoner transport & 1 \\
Property crime & 78 \\
Public order offences & 5 \\
Sexual offences & 9 \\
Traffic/driving offences & 26 \\
Violent crime/assaults & 18 \\
Grand total & 210 \\
\hline
\end{tabular}

From the above wider offence categories, each alert was associated with the relevant offence marker. In some cases, the alert had more than one offence attached to it. In these cases where more than one offence was attached to the alert, all the CCHI values from the offences linked to the alert were added to give a total correct $\mathrm{CCHI}$ value to the alert.

All the alerts (and the associated offences) were then given a crime harm value based on Bland and Ariel (2015). Each offence has a fixed crime harm value as per the CCHI. The CCHI value calculation for each alert is shown in Sidhu (2016). Table 3 shows the total sum of CCHI values assigned to all the first, second and third offences in relation to the 210 alerts; the maximum number of offences attached to any alert was three.

The CCHI values for alerts responded to were compared to the ones not responded to. Similarly, CCHI values for the alerts intercepted compared to not intercepted were calculated. The intercepted ones were further classified as those with a consequence (or a positive outcome as previously described) and those without, again calculating their $\mathrm{CCHI}$ values. From all of the above analysis and checking on the systems, total CCHI value for all the alerts were then calculated. From the above analysis, tests were used to calculate the response rate from the 210 alerts, the intercept rate and the consequence (positive action) rate.

Table 3 Sum of CCHI values assigned to alerts

\begin{tabular}{llll}
\hline & Sum of CHI 1 & Sum of CHI 2 & Sum of CHI 3 \\
\hline Total & $20,218.52$ & 5206.6 & 34.5 \\
\hline
\end{tabular}


Outliers Out of the 210 alerts, one of them had a very high CCHI value of 4760 . As this was the only one with a harm value of over 900 , it is designated as the 'outlier alert' in this study. This outlier alert was linked to offences of armed robbery at gunpoint, illegal possession and use of firearms and attempted burglary. Eleven other outliers were vehicles not linked to criminal offences but to vulnerability issues such as highrisk missing persons. These events have a CCHI value of zero. The analysis has therefore been done in three ways: (1) with the full sample of 210, (2) with the exclusion of the high-CCHI outlier alert and (3) with the exclusion of both the outlier alert and the 11 zero-CCHI-value alerts. The three tiered approach for analysis has been undertaken to firstly remove the disproportionate adverse impact the one outlier alert would have on the findings and then to show the impact zero harm value alerts have on the findings regarding targeting decisions.

The data set of the total sum of CCHI values linked to alerts for response, intercept and consequence are shown in Table 4 . In this table, 1 denotes 'yes' and 0 denotes 'no'.

Power Few Test The 'power few' analysis (Sherman 2007) was conducted to study the ratio of alerts responded to, compared with the total crime harm value targeted from those alerts. This was a measure of the difference between current practice from the sample studied if the Cambridge Crime Harm Index were to be used as the primary targeting tool.

\section{Findings}

Dispatched Responses Out of the 210 alerts, the control centre dispatched police cars to intercept 49 vehicles after live-time alerts. The dispatched response rate was $23.33 \%$ (out of 210 ). These responses only targeted $11.2 \%$ of total CCHI harm across the full sample.

Intercept Rate From the 49 dispatches to the 210 alerts, 33 (67\%) were intercepted by the police, so that $15.71 \%$ of total alerts resulted in a vehicle being intercepted. In terms of CCHI values, only $9 \%$ of the total harm was tackled through intercept police action. The intercepted alerts ranged from offences such as shop theft to serious assault.

Table 4 Total CCHI values for response/intercepts/consequence

\begin{tabular}{ll}
\hline Response (yes/no) & Sum of CCHI values \\
0 & 22,609 \\
1 & 2851 \\
Grand total & 25,460 \\
Intercept & Sum of CCHI values \\
0 & 23,251 \\
1 & 2209 \\
Grand total & 25,460 \\
Consequence & Sum of CCHI values \\
0 & 24,547 \\
1 & 913 \\
Grand total & 25,460 \\
\hline
\end{tabular}


Consequence Rate From the 210 alerts, 20 resulted in a 'consequence' against the suspect in the subject vehicle. This equates to $61 \%$ of the intercepted vehicles and $9.5 \%$ of total alerts resulting in a consequence or positive police action. The total CCHI harm tackled by these 20 'consequence' stops was only $3.6 \%$ for all alerts that month, with the consequences applied to CCHI value of 910 out of a total CCHI of 25,460.

CCHI Values by Dispositions The mean levels of crime harm values were calculated to compare (1) the alerts that were responded to with the ones not responded to, (2) alerts that were intercepted with the ones that were not intercepted and (3) the alerts that had a consequence to the ones that did not. The first author calculated $T$ tests to compare these $\mathrm{CCHI}$ values.

The significance tests for the above groups of alerts were conducted under three different sample conditions: (1) with the highest crime harm value (single alert with a crime harm value of 4760) called the 'outlier alert' included in the dataset (referred to as the full sample), (2) with the 'outlier alert' not in the sample, to establish what impact the exclusion of this single high crime harm alert may have on the test, (3) excluding both the 'outlier alert' and the incidents with 'zero harm value' (total of 12 incidents). The results from these nine independent $t$ tests are captured in Table 5 together with the mean CCHI values for each of the 18 different groups.

Table 5 shows that the mean CCHI value for the alerts that were chosen by the Call Centre for dispatched responses was far lower than the alerts that were not responded to. This analysis was done with the three different sampling methods, as described earlier. The results show that, for the full sample, the average CCHI value of alerts responded to is far less than the alerts not responded to, amounting to less than half $(42 \%)$ of the 'not responded to' category. This shows that, on average, West Midlands

Table 5 Comparison of mean CCHI Values for alerts for dispatched response, intercept and consequences

Mean CCHI values for alerts

(Response/intercept and consequence action)

\begin{tabular}{llll}
\hline & Full sample & $\begin{array}{c}\text { Sample without } \\
\text { outlier alert }\end{array}$ & $\begin{array}{c}\text { Sample without outlier alert and } \\
\text { without zero harm alerts }\end{array}$ \\
$\begin{array}{l}\text { Dispatched response } \\
\text { Yes }\end{array}$ & 59.40 & 59.39 & 60.65 \\
No & 141.30 & 112.25 & 119.78 \\
T test. 'p' value & $0.040^{*}$ & 0.055 & $0.045^{*}$ \\
Intercept & & & 66.94 \\
Yes & 66.90 & 66.94 & 113.43 \\
No & 106.63 & 106.26 & 0.170 \\
T test. 'p' value & 0.125 & 0.245 & 45.64 \\
Consequence & & & 112.42 \\
Yes & 45.60 & 45.64 & $0.045^{*}$ \\
No & 105.80 & 105.81 & 0.069 \\
T test. 'p' value & $0.039^{*}$ & & \\
\hline
\end{tabular}

$* p<0.05$ 
Police in 2015 targeted and responded to alerts that had lower CCHI value per alert than those to which they chose not to respond $(p=0.04)$.

The mean CCHI value of alerts responded to in the sample where the outlier alert is removed is 59.39 and not responded to is $112.25(p=.055)$, a similar result to the result for the full sample (with borderline significance). In the third sample with both the outlier alert and zero CCHI alerts removed, again the mean $\mathrm{CCHI}$ for alerts responded to is far lower at 60.65 compared to 119.78 for the alerts not responded to $(p=.045)$.

The results from the 'intercept' and 'consequences' categories differ from the 'dispatch' results because they depend in part on the dynamics of the interception process. In that sense, they are not only the results of Call Centre decisions, but also of such unknowns as the skill of the wanted drivers in eluding police contact, the interest of the dispatched officers in making an apprehension, and even the colour (affecting visibility on a major freeway) of the vehicles. Nonetheless, the consistent pattern across Table 5 is that the CCHI value is substantially lower for cases in which interceptions and consequences occur than for cases in which they do not. This pattern is powerfully visualized in Fig. 1.

Power Few Analysis A power few analysis (Sherman 2007) of the total 210 live time ANPR alerts shows the cumulative harm distribution of alerts responded to and their associated CCHI harm value. Figure 2 shows the very similar power few distributions of both the full sample and the sample with no 'outlier alert.' The main point of Fig. 1 is to contrast potential targeting practice with the current practice, with the latter indicated by a single square showing just $11 \%$ of harm in the $23 \%$ of alerts receiving $100 \%$ of the actually dispatched responses.

\section{Difference in Crime Harm by Disposition}
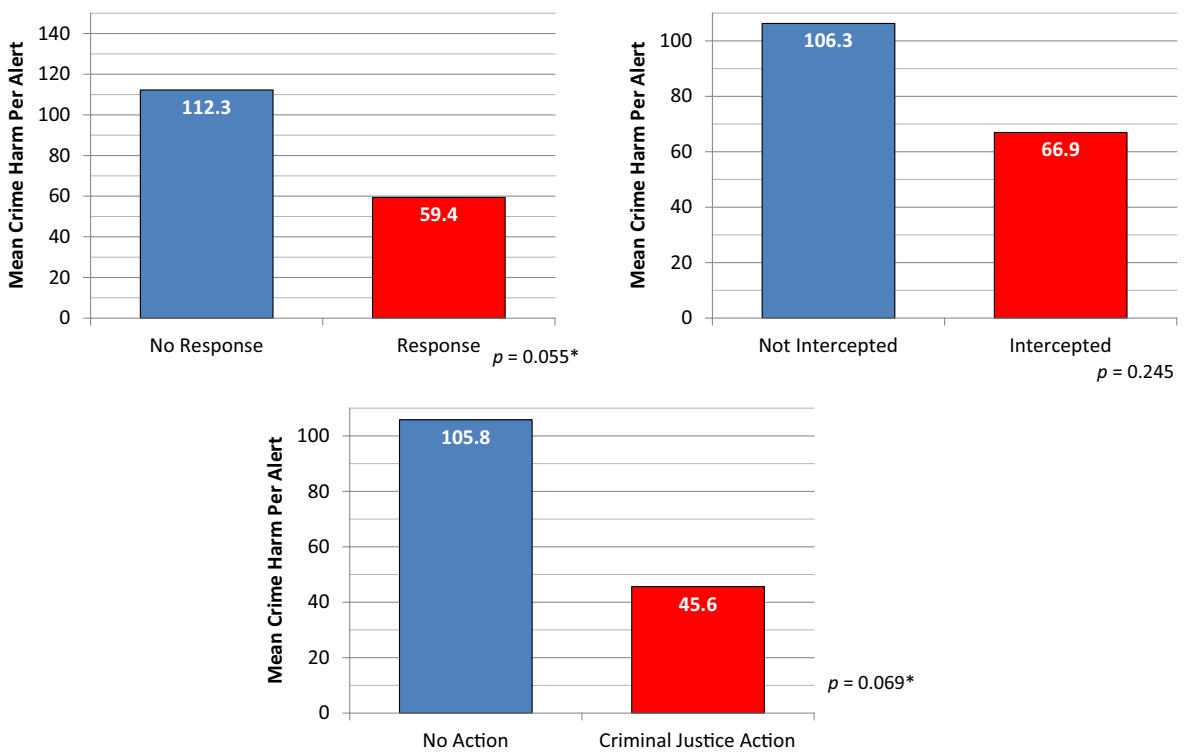

Fig. 1 CCHI harm values by disposition of 210 live-alerts from April 2015, West Midlands Police 


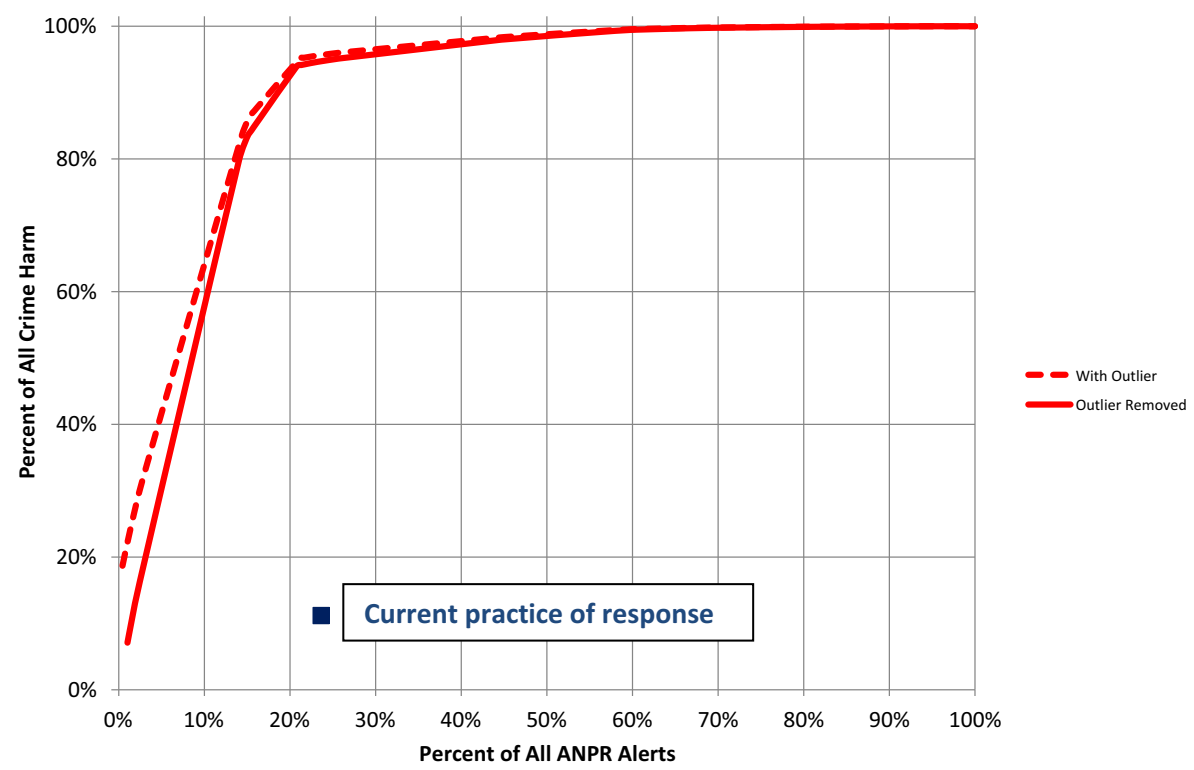

Fig. 2 Power few analysis for ANPR alerts with and without outlier alert

\section{Conclusions}

As of April 2015, live time ANPR alerts were monitored and resourced by a single control centre in the West Midlands Police, called the Regional Control Centre (RCC). The police control room staff in this control centre, operational 24 hours a day throughout the year, are responsible for the decisions to acknowledge the alerts and whether to take any subsequent action. The policy in place in 2015 (West Midlands Police ANPR Alerts Monitoring Policy 2014), gave priority to PNC alerts, followed by force and regional intelligence and then external databases.

The policy implications of the present analysis come from the evidence that the 2015 targeting of resources to live time ANPR alerts was not necessarily based on harm values or crime harm severity. Neither the Cambridge Crime Harm Index nor any other measure of crime severity was directly applied to the prioritisation of these alerts. It is therefore not surprising that the decisions and dispositions should be so sharply at variance with judicial sentencing guidelines.

It is noteworthy that the control room has a full time intelligence specialist working within the ANPR environment. The specialist intelligence officer uses ANPR and other intelligence systems to build as full an intelligence picture as is possible to inform better decision making for the allocation of resources. This system suffers a lack of speed within the IT systems. The requirement to search several databases adds to unnecessary delay in obtaining the relevant information. This on first sight appears to be detrimental to the deployment process. This issue is not within the scope of the study, but it seems relevant to the question of how IT could be re-engineered to incorporate the more systematic priority rankings of the CCHI or some other similar system, such as the UK Office of National Statistics Crime Severity Index. The authors recommend further research and development in this area. 
Any such development must recognize a limitation of crime harm values themselves, especially in cases of missing persons (with a CCHI value of zero). At present, a victim's potential vulnerability is not measured within the Cambridge Crime Harm Index. Nonetheless, this study reports calculations done both with and without these alerts to ensure their impact is fully measured. A parallel decision making approach could be adopted by the RCC staff when resourcing ANPR alerts to take into consideration non-CCHI alerts, such as missing persons enquiries. This would serve to ensure that all vulnerabilities are considered in the decision making process. For the purposes of police resource targeting, the CCHI itself could be developed further to include harm values for vulnerability and public safety issues. This new 'Vulnerability and Crime harm Index' would serve as a single tool used for prioritising live time ANPR alerts for resource allocation.

The parallel decision making approach as described above is recommended for continuation in final decisions being based on professional judgement and discretion, where the control room staff use the CCHI values as supplementary advice rather than as a mandatory decision constraint. For example, if an alert is connected to a high-risk missing person enquiry and it can be seen by the RCC control staff that this attracts no crime harm value as per the proposed targeting model based on CCHI, it would be well and proper for the staff member to allocate resources to such an alert due to the potential for harm rather than actual crime already committed.

Similarly, another important issue that affects the policy is the nature of offences that have a lower CCHI value. An example of such an offence that may raise concerns is 'drink and drive' which has a crime harm value of 1 . The key policy implication in relation to drink drive offences is that traditionally, they have been prioritised based on the nature of the offence. However, it is important to note that the ANPR alert does not tell the control room that the driver is intoxicated, but it identifies that the vehicle is associated with someone who (apparently) has a history of drunk driving and they have been put on a hotlist for that reason. The vehicle maybe driven by someone else or the driver maybe sober at the time. The choice to be made by the control room staff is whether the higher harm alerts should be prioritised over drink drive alerts if police resources were limited. These discussions and arguments are important for policy makers to assist in making better policy choices when deliberating which special offence categories (that have a low $\mathrm{CCHI}$ value) should be targeted and which are not, based on the CCHI values.

In summary, the authors recommend a live time ANPR alert response policy that systematically uses a Crime Harm Index as an advisory tool for focusing police efforts on targeting higher harm alerts. This is, we hope, more likely to result in higher harm reduction than the current system. A trial period is recommended to implement the CCHI targeting advice within any police force, during which the benefits and limitations to be measured including the level of potential harm reduction. The results from the trial would inform long-term ANPR live time alerts targeting policy.

The authors would emphasize that 'resource availability' in terms of police officers and patrol vehicles that were available for deployment at any given time has not been examined as part of this study. It is possible that at certain times of the day there were a higher number of resources available which could have led to higher number of alerts responded to. The converse would also be true during periods of low numbers of patrol cars available for deployment. This issue could be a crucial part of a trial of a new system using a Crime Harm Index, so that resource availability can be factored into the analysis of decisions to 
dispatch responses or not. Just as evidence-based policing may improve police outcomes, more evidence on using better evidence can itself improve evidence-based policing.

Acknowledgements This study was co-funded by a bursary from the College of Policing and by the West Midlands Police for the first author's Master's Degree course in Applied Criminology and Police Management at the Cambridge Police Executive Programme in the Institute of Criminology of the University of Cambridge. The authors wish to thank the first author's colleagues and supervisors within West Midlands Police, including Assistant Chief Constable Marcus Beale for his support and encouragement, as well as Colin Holder, Harry Powar, Derek Roberts and Richard Davin for their patience in assisting with access to the relevant data. Finally, we thank Sir Denis O'Connor of the Cambridge Police Executive Programme for his consistent support and guidance.

Open Access This article is distributed under the terms of the Creative Commons Attribution 4.0 International License (http://creativecommons.org/licenses/by/4.0/), which permits unrestricted use, distribution, and reproduction in any medium, provided you give appropriate credit to the original author(s) and the source, provide a link to the Creative Commons license, and indicate if changes were made.

\section{References}

Bland, M (2014) Targeting escalation in common domestic abuse: how much if any? (Masters Dissertation, University of Cambridge).

Bland, M., \& Ariel, B. (2015). Targeting escalation in reported domestic abuse: evidence from 36,000 callouts. International Criminal Justice Review, 25, 30-53.

Gaikwad, D., \& Barole, B. (2014). A review of Automatic Number Plate Recognition (ANPR) system. International Journal of Innovative Research in Advanced Engineering, 1(1), 04.

Home Office. (2013). National ANPR Standards for Policing: Part 1 - Data Standards. Version 1, May.

Lum, C., Hibdon, J., Cave, B., Koper, C., \& Merola, L. (2011). License plate reader (LPR) police patrols in crime hot spots: an experimental evaluation in two adjacent jurisdictions. Journal of Experimental Criminology, 7, 321-345.

Ramalingam, S., Rhead, M., \& Gurney, R. (2014). Impact of character spacing on the performance of Automatic Number Plate Recognition (ANPR) systems through simulation. In Security Technology (ICCST), 2014 International Carnahan Conference (pp. 1-6). IEEE. https://doi.org/10.1109 /CCST.2014.6987038.

Sherman, L. W. (2007). The power few: experimental criminology and the reduction of harm. Journal of Experimental Criminology, 3(4), 299-321.

Sherman, L. W. (2013). The rise of evidence based policing: targeting, testing and tracking. In M. Tonry (ed.), Crime and Justice America: 1975-2025. Chicago: University of Chicago Press.

Sherman, L. W., Neyroud, P. W., \& Neyroud, E. C. (2016). The Cambridge Crime Harm Index: Measuring Total Harmfrom Crime Based on Sentencing Guidelines. Policing: A Journal of Policy and Practice, 10(3), 171-183. https://doi.org/10.1093/police/paw003.

Sidhu, B. (2016). A descriptive analysis of live time alerts from an automated number plate recognition system: prioritising resource allocation using the crime harm index. Submitted in part fulfilment of the requirements for the Master's Degree in Applied Criminology and Police Management, University of Cambridge.

Taylor, B., Koper, C., \& Woods, D. (2011). Combatting auto theft in Arizona: a randomised experiment with licence plate recognition technology. Final Report to the National Institute of Justice. Washington, DC: Police Executive Research Forum.

Weinborn, C., Ariel, B. \& Sherman, L. (2015). Hotspots vs. harmspots: shifting the focus from counts to harm in the criminology of place (Appendix: The Crime Harm Index "Menu"). Unpublished working paper, Cambridge University.

West Midlands Police Automatic Number Plate Recognition (ANPR) Alarm Monitoring Policy 2014. 